\title{
Neurology
}

\section{Histopathological differences of myotonic dystrophy type 1 (DM1) and PROMM/DM2}

A. Vihola, G. Bassez, G. Meola, et al.

Neurology 2003;60;1854

DOI 10.1212/01.WNL.0000065898.61358.09

This information is current as of April 30, 2013

The online version of this article, along with updated information and services, is located on the World Wide Web at:

http://www.neurology.org/content/60/11/1854.full.html

Neurology ${ }^{\circledR}$ is the official journal of the American Academy of Neurology. Published continuously since 1951, it is now a weekly with 48 issues per year. Copyright (C) 2003 American Academy of Neurology. All rights reserved. Print ISSN: 0028-3878. Online ISSN: 1526-632X.

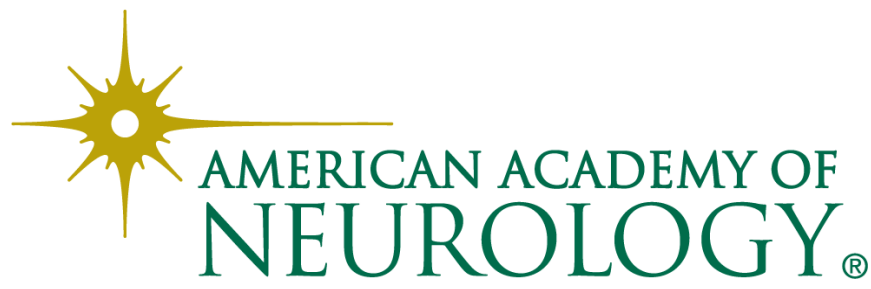




\title{
Histopathological differences of myotonic dystrophy type 1 (DM1) and PROMM/DM2
}

\author{
A. Vihola, MSc; G. Bassez, MD; G. Meola, MD, PhD; S. Zhang, PhD; H. Haapasalo, MD, PhD; \\ A. Paetau, MD, PhD; E. Mancinelli, PhD; A. Rouche, MSc; J.Y. Hogrel, PhD; P. Laforêt, MD; \\ T. Maisonobe, MD; J.F. Pellissier, MD, PhD; R. Krahe, PhD; B. Eymard, MD, PhD; and B. Udd, MD, PhD
}

\begin{abstract}
Muscle biopsy findings in DM2 have been reported to be similar to those in DM1. The authors used myosin heavy chain immunohistochemistry and enzyme histochemistry for fiber type differentiation on muscle biopsies. Their results show that DM2 patients display a subpopulation of type 2 nuclear clump and other very small fibers and, hence, preferential type 2 fiber atrophy in contrast to type 1 fiber atrophy in DM1 patients.
\end{abstract}

NEUROLOGY 2003;60:1854-1857

Myotonic dystrophies are categorized as DM1 (myotonic dystrophy, Steinert's disease; OMIM 160900), caused by a $(\mathrm{CTG})_{\mathrm{n}}$ expansion mutation in $19 \mathrm{q} 13$, and DM2 (proximal myotonic myopathy [PROMM]; OMIM 602668), caused by a (CCTG) ${ }_{n}$ expansion mutation in $3 q 21 .^{1,2}$ Both myotonic dystrophies are autosomal dominant multiorgan syndromes with striking similarities in clinical manifestations and muscle histopathology. ${ }^{3-5}$ Distinct features of DM2 compared with DM1 include preferentially proximal muscle weakness and muscle biopsy type 1 fiber predominance, higher frequency of nuclear clump fibers, and lack of type 1 fiber atrophy as seen in DM1.6-8 The possibility of type 2 fiber atrophy has been raised with DM2. ${ }^{9}$ We studied the histopathology of DM1 and DM2.

Patients and methods. Deltoid, biceps brachii, and vastus lateralis muscle biopsies from nine patients from three European countries were re-examined. All had PROMM phenotype and expanded DM2 alleles in the range of 5 to $25 \mathrm{~kb}$ as assessed by Southern analysis. The biopsies were previously taken for diagnostic purposes and used for this study after informed consent from the patients. The Table provides a description of clinical features of the DM2 patients in this study. Electromyography (EMG) showed myotonia for all patients.

Additional material related to this article can be found on the Neurology Web site. Go to www.neurology.org and scroll down the Table of Contents for the June 10 issue to find the title link for this article.
Muscle biopsies. Deltoid muscle biopsies were obtained from three French DM2 patients, two of whom originated from France and one from Serbia. Detailed clinical features of one patient (F3) from the series have been previously reported. ${ }^{9}$ Vastus lateralis muscle biopsies from three patients from two unrelated Finnish DM2 families not previously reported were examined (FIN1 and FIN3 are cousins). Biceps brachii muscle biopsies were obtained from three patients from unrelated Italian DM2 families. Control subjects were age-matched and mutation-verified DM1 patients from different families (deltoid, three; vastus, three; biceps, two), with similar muscle weakness shown on muscle biopsy, and one recessive congenital myotonia patient with homozygous R894X mutation in the CLCN1 gene.

Histologic procedure. Serial transverse muscle cryostat sections $6 \mu \mathrm{m}$ and $10 \mu \mathrm{m}$ thick were cut for immunohistochemical (IHC) and routine histochemical stainings, respectively, with hematoxylin and eosin (H-E), Gomori's trichrome, and nicotinamide adenine dinucleotide (NADH) tetrazolium reductase.$^{10} \mathrm{~A}$ standard myofibrillar ATPase staining protocol was used after preincubation at $\mathrm{pH} 4.3, \mathrm{pH} 4.6$, and $\mathrm{pH} 9.4$ or $10.4 .^{10}$ Ventana Nexes automated immunostainer (Ventana Medical Systems, Tucson, AZ) was used for IHC, with avidin-biotin-complex method followed by diaminobenzidine (DAB) detection. Monoclonal primary antibodies against different myosin heavy chain (MHC) isotypes were used at the following dilutions: MHCfast, 1:400 (My-32, Sigma Chemical Co., St. Louis, MO); MHCslow, 1:5,000 (NOQ7.5.4D, Sigma); and MHCd (developmental), 1:10 (RNMy2/9D2, Novocastra Laboratories, Newcastle upon Tyne, UK). Quantitative evaluation of fiber diameter was made with Scion Image (Scion Corporation, Frederick, MD) on images taken with a microscope $(3.2 \times 10$ original magnification) and sections stained with slow and fast MHC IHC. The size of muscle fibers was assessed by measuring the "smallest fiber diameter." The number of muscle fibers evaluated in each sample ranged from 537 to 5,151 (see supplementary content on the Neurology Web site). All data were

From the Department of Neurology (Dr. Udd and A. Vihola), Vaasa Central Hospital, Vaasa, Finland; Myology Institute (Drs. Bassez, Rouche, Hogrel, Laforêt, and Eymard), Salpêtrière Hospital, Paris, France; Department of Neurology (Dr. Meola), University of Milan, San Donato Hospital, San Donato Milanese, Milan, Italy; Human Cancer Genetics Program (Drs. Zhang and Krahe), Department of Molecular Virology, Immunology and Medical Genetics, Comprehensive Cancer Center, Ohio State University, Columbus, OH; Department of Pathology (Dr. Haapasalo), Tampere University Hospital, Tampere, Finland; Department of Pathology (A. Paetau), University of Helsinki, Finland; Department of Physiology and General Biochemistry (Dr. Mancinelli), University of Milan, Italy; Department of Neuropathology (Dr. Maisonobe), Salpêtrière Hospital, Paris, France; Department of Pathology and Neuropathology (Dr. Pellissier), La Timone Hospital, Marseilles, France; and Section of Cancer Genetics, Department of Molecular Genetics (Dr. Krahe), University of Texas M.D. Anderson Cancer Center, Houston, TX.

Authors Vilhola and Bassez contributed equally to the study as first authors, and Drs. Udd and Eymard contributed equally as last authors.

Supported by Medical Grant Foundation Liv \& Hälsa r.f., Medical Research Fund of Vaasa Hospital District, Association Francaise contre les Myopathies (AFM), MURST (G.M. and E.M.), Muscular Dystrophy Association, USA, and the NIH (R01 AR48171).

Presented in part at the 53rd Annual Meeting of American Academy of Neurology, May 5-11, 2001.

Received May 13, 2002. Accepted in final form February 12, 2003

Address correspondence and reprint requests to Dr. Bjarne Udd, Department of Neurology, Vaasa Central Hospital, FIN-65130 Vaasa, Finland; e-mail: Bjarne.Udd@vshp.fi 
Table Clinical findings of the DM2 patients included in this study

\begin{tabular}{|c|c|c|c|c|c|c|c|c|}
\hline Patient & $\begin{array}{l}\text { Sex } \\
\mathrm{M} / \mathrm{F}\end{array}$ & Age & $\begin{array}{l}\text { Onset } \\
\text { age }\end{array}$ & $\begin{array}{c}\text { First } \\
\text { symptom }\end{array}$ & $\begin{array}{l}\text { Clinical muscle } \\
\text { signs }\end{array}$ & Systemic signs & $\begin{array}{l}\text { Other } \\
\text { findings }\end{array}$ & $\begin{array}{l}\text { Biopsied muscle } \\
\text { (MRC score) }\end{array}$ \\
\hline \multicolumn{9}{|l|}{ French } \\
\hline F1 & M & 49 & 40 & $\mathrm{Wk}$ & Wk & $\mathrm{Ca}, \mathrm{B}, \mathrm{Hy}$ & - & Deltoid (4) \\
\hline F3 & M & 45 & 41 & $\mathrm{Wk}$ & Wk, P & $\mathrm{Ca}, \mathrm{B}, \mathrm{D}, \mathrm{IR}, \mathrm{Hy}, \mathrm{G}$ & $\begin{array}{l}\text { At, } \\
\mathrm{HCh}\end{array}$ & Deltoid (4) \\
\hline $\mathrm{F} 4$ & M & 57 & 55 & $\mathrm{P}$ & Wk, P & $\mathrm{Ca}, \mathrm{Hy}$ & $\operatorname{Tr}$ & Deltoid (5) \\
\hline \multicolumn{9}{|l|}{ Finnish } \\
\hline FIN1 & M & 39 & 36 & CK & $\mathrm{Wk}$ & $\mathrm{Ca}$ & $\mathrm{HCh}$ & Vastus lateralis (5) \\
\hline FIN2 & $\mathrm{F}$ & 34 & 27 & St & - & - & - & Vastus lateralis (5) \\
\hline FIN3 & $\mathrm{F}$ & 42 & 32 & $\mathrm{St}, \mathrm{Ca}$ & Wk & $\mathrm{Ca}$ & - & Vastus lateralis (5) \\
\hline \multicolumn{9}{|l|}{ Italian } \\
\hline I1 & $\mathrm{F}$ & 60 & 40 & $\mathrm{Wk}$ & Wk, My & $\mathrm{Ca}$ & - & Biceps brachii (4) \\
\hline I2 & M & 57 & 50 & Wk & Wk, My & $\mathrm{Ca}$ & - & Biceps brachii (5) \\
\hline I3 & M & 59 & 45 & Wk, P & $\mathrm{Wk}$ & $\mathrm{Ca}$ & - & Biceps brachii (5) \\
\hline
\end{tabular}

At = severe atherosclerosis; $\mathrm{B}=$ balding; $\mathrm{Ca}=$ cataracts; $\mathrm{CK}=$ serum $\mathrm{CK}$ elevation; $\mathrm{D}=$ diabetes mellitus; $\mathrm{G}=$ elevated gamma glutamyltransferase; $\mathrm{HCh}=$ hypercholesterolemia; $\mathrm{Hy}=$ hyperhidrosis; $\mathrm{IR}=$ insulin resistance; $\mathrm{My}=$ clinical myotonia; $\mathrm{P}=$ pain; $\mathrm{Pt}=$ ptosis; $\mathrm{St}=$ stiffness; $\mathrm{Tr}=$ tremor; $\mathrm{Wk}=$ weakness.

elaborated using Microcal Origin (Microcal Software Inc., Northampton, MA). The metahistograms were normalized to normal mean diameter for men and women. Atrophy and hypertrophy factors were also calculated. ${ }^{10}$

Results. Common histopathologic findings. Routine histochemical stainings of DM2 muscle sections showed myopathic changes, including increased fiber size variation and internalized nuclei (figure 1). Increases of connective tissue, fat replacement, or necrotic fibers were rarely observed. Structural changes mainly consisted of occasional moth-eaten fibers, whereas subsarcolemmal masses and ring fibers were particularly rare. Occasional rimmed vacuolar fibers or ragged-red fibers (RRF) were encountered in some specimens. Central nuclei were frequent in DM1 and DM2 biopsies, and many small fibers with nuclear clumps were observed in most DM2 specimens (see figure 1). Rounded or thin angular atrophic fibers were usually scattered, whereas fiber type grouping or targetoid fibers were not encountered.
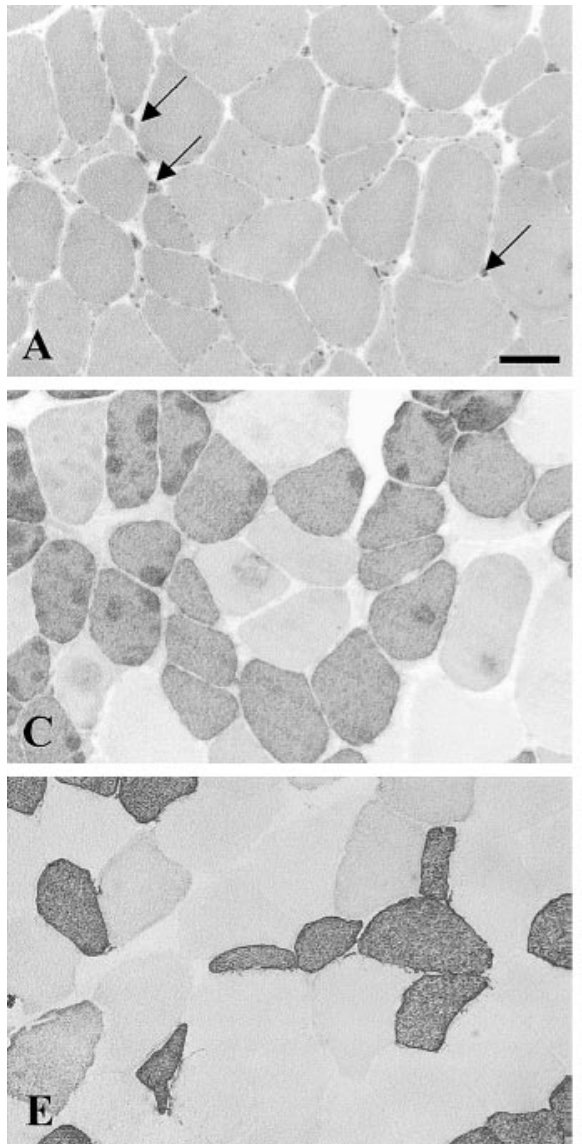

Figure 1. Panel showing vastus lateralis histopathology of DM2 compared with DM1. (A through D) Finnish DM2 Patient FIN1. (E and F) Italian DM1 patient. (A) Hematoxylin and eosin $(H$ E); (B) ATPase pH 10.4; (C) Immunohistochemical (IHC), MHCslow; (D) IHC, MHCfast; (E) IHC, MHCslow; and (F) IHC, MHCfast. The population of small type 2 fibers in DM2 muscle is more distinguishable when IHC staining is used instead of ATPase. In the DM1 control muscle, no population of small fibers of either type is present. Arrows indicate nuclear clump fibers. Scale bar $=100 \mu \mathrm{m}$. 


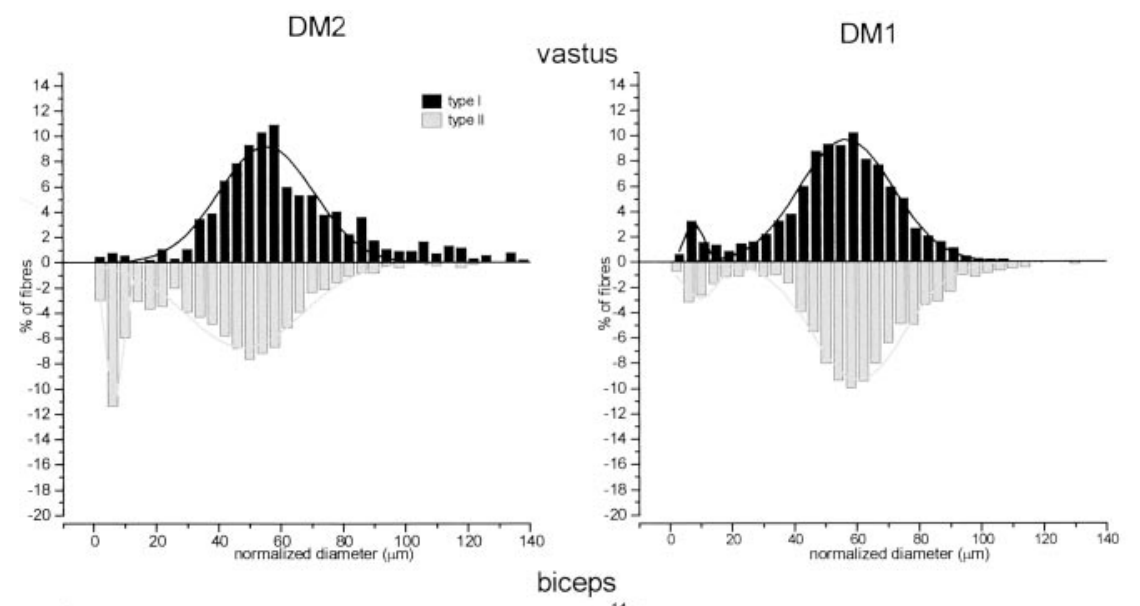

Figure 2. Metahistograms showing the preferential atrophy of type 2 fibers in vastus lateralis, biceps, and deltoid muscles from DM2 patients, and marked type 1 fiber atrophy and slight type 2 atrophy in DM1 patients. The
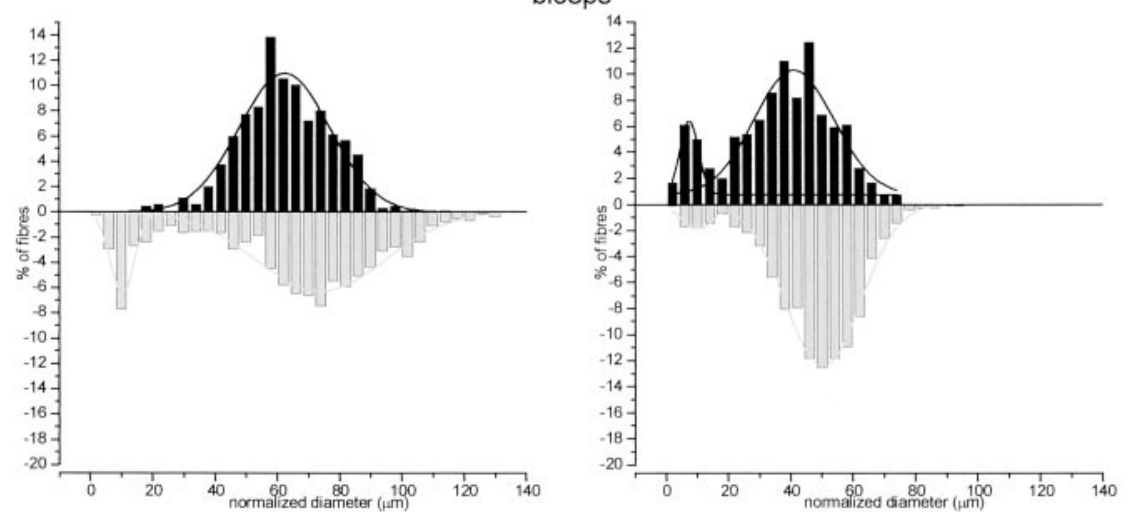
results are based on IHC stained sections. Atrophy (A) and hypertrophy $(H)$ factors for type 1 and type 2 fibers: vastus lateralis; DM2 vs DM1: A1, 70.91 vs 227.01; A2, 739.64 vs 247.36; H1, 473.56 vs $100.31 ; \mathrm{H} 2,100.33$ vs 270.45 ; biceps; DM2 vs DM1: A1, 18.90 vs 538.17; A2, 252.11 vs 190.48; H1, 135.43 vs 0.00 ; H2, 680.28 vs 11.58 ; deltoid; DM2 vs DM1: A1, 152.64 vs 325.76; A2, 1,232.96 vs 180.94; H1, 179.36 vs 47.18 ; $H 2,287.23$ vs 54.55 . Upper limits for the value of atrophy and hypertrophy factors in vastus lateralis: (men) A1, 150; A2, 150; H1, 150;

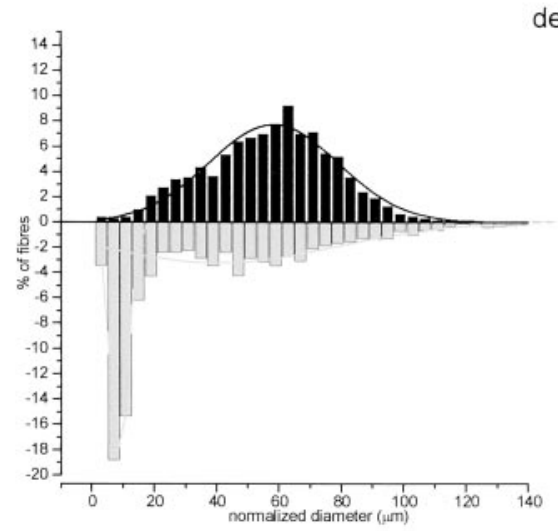

deltoid

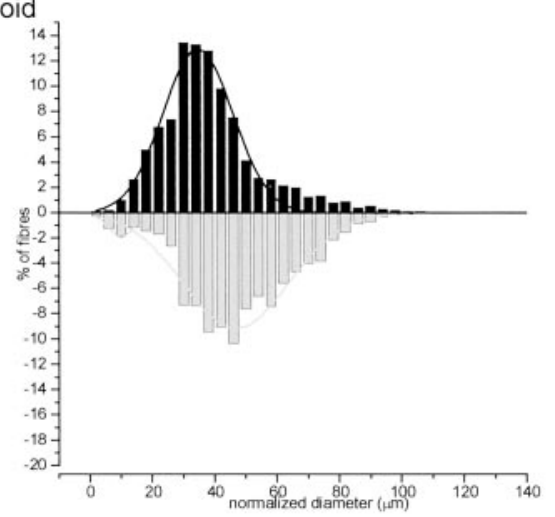
H2, 400; (women) A1, 100; A2, 200; H1, 400; H2, 150; and biceps (men) A1, 150; A2, 150; H1, 300; H2, 500; (women) A1, 100; A2, 150; H1, 200; H2, $150 .^{10}$

Fiber type analysis. The metahistograms based on IHC data in figure 2 show preferential fiber type 2 atrophy in vastus lateralis, biceps, and deltoid muscles from DM2 patients. Hypertrophy of type 2 fibers in biceps of DM2 patients is also evident. In DM1 patients, marked atrophy of type 1 fibers and slight atrophy of type 2 fibers are present in all muscles. A control sample from the recessive congenital myotonia patient revealed no preferential type 2 atrophy (data not shown). A subpopulation of small fibers (diameter $\leq 20 \mu \mathrm{m}$ ), including all the nuclear clump fibers (which expressed almost exclusively fast MHC [type 2 fiber] isoform), was seen in the DM2 biopsies. Nuclear clumps and other small type 2 fibers were prominent in some vastus lateralis and deltoid samples even at onset of symptoms. IHC and the ATPase method gave identical fiber type distribution patterns for fibers more than 40 $\mu \mathrm{m}$ in diameter, but many fibers less than $20 \mu \mathrm{m}$ in diameter, well identified by MHC IHC, were not readily discernible with H-E and ATPase (see figure 1). A small proportion of fibers of all sizes expressed fast and slow MHC isoforms, and few regenerating fibers expressing the developmental myosin isotype were observed. The presence of $2 \mathrm{~B}$ fibers was confirmed in all DM2 biopsies in this study, although not in constant proportions (see table E-1 on the Neurology Web site for a summary of the key figures of the histographic analysis). The calculated atrophy and hypertro- phy factors are in full agreement with the results derived from other methods in this study.

Discussion. Our study shows preferential type 2 fiber atrophy in DM2 and absence of type 1 fiber atrophy in contrast to DM1. IHC determination of fiber type distribution revealed many small fibers (diameter $\leq 20$ $\mu \mathrm{m})$, including the nuclear clump fibers, practically all of which were identified as type 2 fibers. This study showed a variable fiber type distribution in DM2 depending on muscle site. In particular, the previously described type 1 fiber predominance was only attested in deltoid biopsies and was not confirmed in vastus lateralis and biceps brachii muscles. Hypertrophy was variable in both fiber types, which may be the result of secondary compensation or myotonia.

Further studies will be required to determine the fiber type of nuclear clump fibers appearing in more 
severely affected DM1 muscles and whether the different extremely small type 2 fibers in DM2 belong to different subpopulations.

Muscle biopsy is rarely needed for DM1 diagnosis, but for DM2 the situation is different because the clinical findings are milder and less pathognomonic. The histopathologic findings reported here might help the diagnostic procedure to select patients for further DM2 molecular genetic verification.

\section{Acknowledgment}

The authors thank Dr. M. Fardeau, who initiated the morphologic study in the French group, and Dr. J. Pouget, who is actively involved in the French PROMM study.

\section{References}

1. Ashizawa T. The international myotonic dystrophy consortium (IDMC): new nomenclature and DNA testing guidelines for myotonic dystrophy type 1 (DM1). Neurology 2000;54:1218-1221.
2. Liquori C, Ricker K, Moseley ML, et al. Myotonic dystrophy type 2 caused by a CCTG expansion in intron 1 of ZNF9. Science 2001;293: $864-867$

3. Ricker K, Koch MC, Lehmann-Horn F, et al. Proximal myotonic myopathy: a new dominant disorder with myotonia, muscle weakness, and cataracts. Neurology 1994;44:1448-1452.

4. Udd B, Krahe R, Wallgren-Pettersson C, Falck B, Kalimo H. Proximal myotonic dystrophy - a family with autosomal dominant muscular dystrophy, cataracts, hearing loss and hypogonadism: heterogeneity of proximal myotonic syndromes? Neuromuscul Disord 1997;7:217-228.

5. Day JW, Ricker K, Jacobsen JF, et al. Myotonic dystrophy type 2: molecular, diagnostic and clinical spectrum. Neurology 2003, in press.

6. Moxley RT. Proximal myotonic myopathy: mini-review of a recently delineated clinical disorder. Neuromuscul Disord 1996;6:87-93.

7. Harper PS. Myotonic dystrophy, 3rd ed. London: Saunders, 2001.

8. Moxley RT, Meola G, Udd B, Ricker K. Report of the 84th ENMC workshop: PROMM (proximal myotonic myopathy) and other myotonic dystrophy-like syndromes: 2nd workshop. 13-15th October 2000, Loosdrecht, The Netherlands. Neuromuscul Disord 2002;12:306-317.

9. Bassez G, Attarian S, Laforêt P, et al. Myopathie proximale avec myotonie (PROMM): étude clinique et histologique. Rev Neurol 2001;157: 209-218.

10. Dubowitz V, ed. Muscle biopsy. A practical approach. London, Philadelphia, Toronto: Bailliere Tindall, 1985.

\title{
A missense mutation in the mitochondrial ND5 gene associated with a Leigh-MELAS overlap syndrome
}

\author{
Marco Crimi, PhD; Sara Galbiati, MD; Isabella Moroni, MD; Andreina Bordoni, BS; \\ Maria Paola Perini, MD; Eleonora Lamantea, PhD; Monica Sciacco, MD; Massimo Zeviani, MD; \\ Ida Biunno, PhD; Maurizio Moggio, MD; Guglielmo Scarlato, MD †; and Giacomo Pietro Comi, MD
}

\begin{abstract}
A 13084 A-> T missense mutation in the mitochondrial ND5 gene was identified in a 16-year-old boy affected with a progressive neurodegenerative disorder combining features of Leigh and MELAS (mitochondrial encephalomyopathy, lactic acidosis, and strokelike episodes) syndromes. Muscle biopsy analysis revealed partial complex I deficiency. The mutation presented a variable degree of heteroplasmy in the patient's tissues. This finding underlines the contribution of mtDNA-encoded complex I subunits in the etiology of complex I deficiency associated with encephalopathy.
\end{abstract}

NEUROLOGY 2003;60:1857-1861

Isolated complex I deficiency is a common enzyme defect among the group of oxidative phosphorylation disorders. ${ }^{1}$ Human complex I consists of at least 36 nuclear DNA (nDNA)- and 7 mitochondrial DNA (mtDNA)-encoded subunits. Leigh syndrome (LS) or Leigh-like disease is the most common phenotype associated with an isolated complex I deficiency, representing up to $50 \%$ of total cases, although isolated myopathies, MELAS (mitochondrial encephalomyopathy, lactic acidosis, and strokelike episodes) syn- drome, and Leber's hereditary optic neuropathy (LHON) presentations are also described. ${ }^{1}$

Here we report a novel ND5 heteroplasmic missense mutation associated with severe progressive infantile encephalopathy, with features of LS and MELAS. The proband's mother, carrying a lower mutation level, presents recurrent migraine attacks and bilateral optic atrophy. These data expand the molecular etiology of partial isolated complex I deficiency.

\footnotetext{
$\dagger$ Deceased.

From the Dino Ferrari Center (Drs. Crimi, Galbiati, Perini, Sciacco, Moggio, Scarlato, and Comi, A. Bordoni), Department of Neurological Sciences, University of Milan, I.R.C.C.S. Ospedale Maggiore Policlinico; Divisions of Neuropediatrics (Dr. Moroni) and Biochemistry and Genetics (Drs. Lamantea and Zeviani), National Neurological Institute-I.R.C.C.S., C. Besta; and Istituto Tecnologie Biomediche Avanzate (ITBA)-CNR and Centro Interdisciplinare Studi bio-molecolari e applicazioni Industriali (CISI) (Dr. Biunno), Milan, Italy.

Supported by the Associazione Amici del Centro Dino Ferrari.

Received November 5, 2002. Accepted in final form February 14, 2003.

Address correspondence and reprint requests to Dr. Marco Crimi, Dipartimento di Scienze Neurologiche, Ospedale Maggiore Policlinico (Pad.ne Ponti), Via F Sforza 35, 20122 Milan, Italy; e-mail: neurogene@policlinico.mi.it
} 


\section{Histopathological differences of myotonic dystrophy type 1 (DM1) and PROMM/DM2}

A. Vihola, G. Bassez, G. Meola, et al.

Neurology 2003;60;1854

DOI 10.1212/01.WNL.0000065898.61358.09

\section{This information is current as of April 30, 2013}

\section{Updated Information \& Services \\ Supplementary Material}

References

Citations

Subspecialty Collections

Permissions \& Licensing

Reprints including high resolution figures, can be found at: http://www.neurology.org/content/60/11/1854.full.html

Supplementary material can be found at: http://www.neurology.org/content/supp1/2003/05/22/60.11.1854 .DC1.html

This article cites 6 articles, 3 of which can be accessed free at: http://www.neurology.org/content/60/11/1854.full.html\#ref-list1

This article has been cited by 8 HighWire-hosted articles: http://www.neurology.org/content/60/11/1854.full.html\#relatedurls

This article, along with others on similar topics, appears in the following collection(s):

Ion channel gene defects

http://www.neurology.org/cgi/collection/ion_channel_gene_def ects

Muscle disease

http://www.neurology.org/cgi/collection/muscle_disease Trinucleotide repeat diseases

http://www.neurology.org/cgi/collection/trinucleotide_repeat_di seases

Information about reproducing this article in parts (figures, tables) or in its entirety can be found online at:

http://www.neurology.org/misc/about.xhtml\#permissions

Information about ordering reprints can be found online: http://www.neurology.org/misc/addir.xhtml\#reprintsus 